\title{
The Characteristics of Perceived Difficulties in Everyday Technology Use among Individuals with Acquired Brain Injury Compared to That among Controls
}

\author{
Osamu Nakata1 ${ }^{*}$, Rumi Tanemura², Toru Nagao ${ }^{2}$, Kazue Noda², Jiro Sagara ${ }^{3}$ \\ ${ }^{1}$ Department of Rehabilitation, Naragakuen University, Nara, Japan \\ ${ }^{2}$ Graduate School of Health Sciences, Kobe University, Hyogo, Japan \\ ${ }^{3}$ Graduate School of Arts and Design, Kobe Design University, Kobe, Japan \\ Email: *otnakata@nara-su.ac.jp, rumtan@people.kobe-u.ac.jp, nagao@kobe-u.ac.jp,noda@kobe-u.ac.jp, sagara-j@kobe-du.ac.jp
}

How to cite this paper: Nakata, O., Tanemura, R., Nagao, T., Noda, K. and Sagara, J. (2020) The Characteristics of Perceived Difficulties in Everyday Technology Use among Individuals with Acquired Brain Injury Compared to That among Controls. Journal of Behavioral and Brain Science, 10, 410-419.

https://doi.org/10.4236/jbbs.2020.1010026

Received: August 21, 2020

Accepted: October 20, 2020

Published: October 23, 2020

Copyright $\odot 2020$ by author(s) and Scientific Research Publishing Inc. This work is licensed under the Creative Commons Attribution International License (CC BY 4.0).

http://creativecommons.org/licenses/by/4.0/

\begin{abstract}
Objectives: People with acquired brain injury (ABI) have various difficulties when using everyday technology (ET) in their daily life. The aim of this study was to reveal the characteristics of perceived difficulties of people with ABI when using ET through a comparison with the control group. Method: We recruited participants in the Kansai area and Okayama prefecture between 2010 and 2015. A total of 24 participants (18 males and 6 females; aged 20 to 62 years; mean age: $42.6 \pm 13.3$ years) with ABI and 26 healthy controls were interviewed about their perceived difficulties using ET via the Everyday Technology Use Questionnaire revised Japanese version (ETUQ-Japan). Results: Compared to the controls, the mean number of ETs used by people with ABI was significantly lower. When various difficulties arose, they were unable to independently manage ET, requiring the assistance of caregivers. Conclusion: It is necessary for the medical staff, involved in the home life of patients with $\mathrm{ABI}$ to consider the patient's perceived difficulties when using ET.
\end{abstract}

\section{Keywords}

Acquired Brain Injury, Cognitive Impairment, Everyday Technology

\section{Introduction}

In Japan, the total number of patients with cognitive impairment has been estimated to be approximately 500,000 [1], with an annual diagnosis of 2884 new patients with acquired brain injury (ABI) [2]. ABI is primarily caused by head 
trauma, cerebrovascular accident, or hypoxic encephalopathy. Several people with $\mathrm{ABI}$ have impairments, such as memory disorder, attention disorder, and executive dysfunction [3]. In many cases following ABI, social isolation has been observed [4], along with activity limitation [5] and participation restriction [6] [7]. It is well known that these impairments affect the daily lives of not only people with ABI but also their caregivers [8] [9].

Everyday technology (ET) is defined as technological, electronic, and mechanical products and services, and comprises both common (i.e., microwave oven, air conditioner) and newly developed (i.e., IC e-card, internet banking) products and services [10] [11]. The use of ET by people with ABI entails several challenges during activities of daily living. Many people with ABI have been reported to have some difficulties when using ET [12]. The use of ET is associated with generic activities of daily living. [13]. Difficulty in ET use has been shown to be significantly correlated with the global severity of disability after ABI [14]. The difficulties in using ET were related not only to the technology itself but also to the interactions between the technology, task, person, and environment [15]. ABI patients with various types of cognitive disorders can benefit from ET [16]. Social participation requires the ability to use ET [17]. There are discrepancies between the abilities of people with ABI to manage ET in relation to the demands imposed by the technology on them in their work setting [18].

Indeed, there have been several studies on the relationships between the situation of ET use and the life of people with ABI; however, these studies did not include any comparison of the findings with a healthy control group. A study was conducted previously to compare the number of ETs used among elderly adults with mild cognitive impairment (MCI) and controls. According to this study, elderly adults with MCI use a significantly lower number of ETs [19]. Fallahpour et al. identified that the perceived difficulty in using ET is significantly increased among individuals with $\mathrm{ABI}$ with severe to moderate disability compared with controls [20], but this study did not include the situation of using ET. Occupational therapists are required to pay attention to the extent to which people with ABI have difficulty using ET due to their cognitive dysfunction [21].

The aim of this study was to identify and describe the characteristics of perceived difficulties of using ET by people with ABI in their daily lives by comparing them with controls.

\section{Methods}

\subsection{Participants}

The inclusion criteria for the ABI participants were as follows: 1) having a cognitive impairment caused by brain injury, 2) no physical dysfunction or barely affected by physical dysfunction that prevents ET use, 3) ABI diagnosed by a physician, 4) having communicative ability to participate in our interviews, and 5) living at home. Upon commencing research, requests for research coopera- 
tion were sent to eight general hospitals, clinics, community workshops specialized in cognitive disorders, and Patient-Family Associations in the Kansai area and Okayama prefecture; participants were recruited between 2010 and 2013. Of the total of 27 people introduced, 24 participants fulfilled the inclusion criteria and agreed to participate in this study after being provided written explanations. The ABI group included 24 participants, of which 18 were men and six were women, with ages from 20 to 62 years with a mean age of $42.6 \pm 13.3$ years. Causes of head injuries included head trauma (15 participants), cerebrovascular accident (six participants) and hypoxic encephalopathy (three participants). The inclusion criteria for the controls were as follows: a) no previous history of head trauma or cerebrovascular accidents and b) no subjective impairments in physical or cognitive function affecting daily life. They were randomly recruited from a school in Hyogo prefecture to which the first author belongs, related hospitals, facilities, and residential neighborhoods. They were provided with written explanations for cooperation before they participated in the study. Controls subjects consisted of 26 participants, of whom 18 were men and eight were women, with ages ranging from 24 to 72 years and a mean age of $42.5 \pm 13.5$ years. Informed consent was obtained from all participants. This study proposal was approved by the Ethical Committee of the Kobe University Graduate School of Health Sciences.

\subsection{Tools}

The Everyday Technology Use Questionnaire revised Japanese version (ETUQ-Japan) was used to assess perceived difficulties in ET use. The original ETUQ is a semi-structured standardized interview questionnaire that contains questions concerning perceived difficulty in using ET among elderly people with cognitive deficits living at home [11] [14]. Original ETUQ is composed of 93 items organized into eight domains: household activities, activities in the home, personal care, power tools, accessibility, data and telecommunications, economy and shopping, and transportation. The ETUQ-Japan translated and revised by Tanemura and her colleagues, is composed of 101 items organized into eight domains [22].

Each interview was conducted using ETUQ-Japan. According to the manual, items that were not available or never used by subjects were rated as "not relevant" [20]. The items relevant to the use of ET, were categorized based on ability: 1) "use independently without difficulty", 2) "use independently with difficulty", or 3) "use with assistance of someone else". The value obtained by dividing the number of ETs included in each option by the total number of ETs used was defined as "situation of using ET". The average of the "situation of using ET" was then calculated for each group.

\subsection{Data Analysis}

To verify the condition of ET by subjects with ABI, "the number of using ET" 
and "the number of using ET in each domain" were compared with controls. The ratio of using ET of "use independently without difficulty" and "use independently with difficulty" and "use with assistance of someone else" were compared between subject with $\mathrm{ABI}$ and control subject. We performed these comparisons between subjects with $\mathrm{ABI}$ and control subjects by conducting Wilcoxon rank sum test. For data analysis, SPSS version 20.0 for windows was used for this study.

\section{Results}

The characteristics of the participants are summarized in Table 1 . There were no significant differences between the two groups in average age, gender ratio, living situation, and employment situation.

The mean number of ETs used by subject with ABI and subject in the controls living at home were $34.7 \pm 8.3$ and $54.9 \pm 5.4$, respectively, of 101 items that were included in the ETUQ-Japan (Figure 1). The mean number of ETs used by subject with ABI was significantly lower than that in the control group $(\mathrm{p}<0.01)$.

The mean number of ETs used by subject with ABI was significantly lower in seven domains, except for the accessibility domain (Figure 2).

Significant differences were observed between people with ABI and the control group in "use independently without difficulty" (ABI 57.6\%/control 80.7\%, $\mathrm{p}<0.05$, same as below) and "use with assistance of someone else" $(20.7 \% / 2.0 \%$, $\mathrm{p}<0.01)$. There was no significant difference in "use independently with difficulty" (21.6\%/17.3\%) between the two groups (Figure 3).

Table 1. Characteristics of the participants in this study.

\begin{tabular}{|c|c|c|c|}
\hline & \multirow{2}{*}{$\mathrm{ABI}(\mathrm{n}=24)$} & \multirow{2}{*}{ control $(\mathrm{n}=26)$} & \multirow{2}{*}{$\begin{array}{l}\text { Comparison Test } \\
\text { Independent } t \text {-tes }\end{array}$} \\
\hline & & & \\
\hline \multicolumn{4}{|l|}{ Age (years) } \\
\hline Mean (SD) & $42.6(13.3)$ & $42.5(13.5)$ & \multirow{2}{*}{$\mathrm{p}>0.05$} \\
\hline Range & $20-62$ & $24-72$ & \\
\hline Gender (n) & & & Pearson $\chi^{2}$ \\
\hline male & 18 & 18 & \multirow{2}{*}{$\mathrm{p}>0.05$} \\
\hline female & 6 & 8 & \\
\hline Living situation (n) & & & Pearson $\chi^{2}$ \\
\hline with family & 22 & 21 & \multirow{2}{*}{$\mathrm{p}>0.05$} \\
\hline alone & 2 & 5 & \\
\hline Employment situations (n) & & & Pearson $\chi^{2}$ \\
\hline unemployed & 11 & 12 & \multirow{2}{*}{$\mathrm{p}>0.05$} \\
\hline employment & 13 & 14 & \\
\hline \multicolumn{4}{|l|}{ Type of ABI (n) } \\
\hline head trauma & 15 & & \\
\hline cerebrovascular accident & 6 & & \\
\hline hypoxic encephalopathy & 3 & & \\
\hline
\end{tabular}




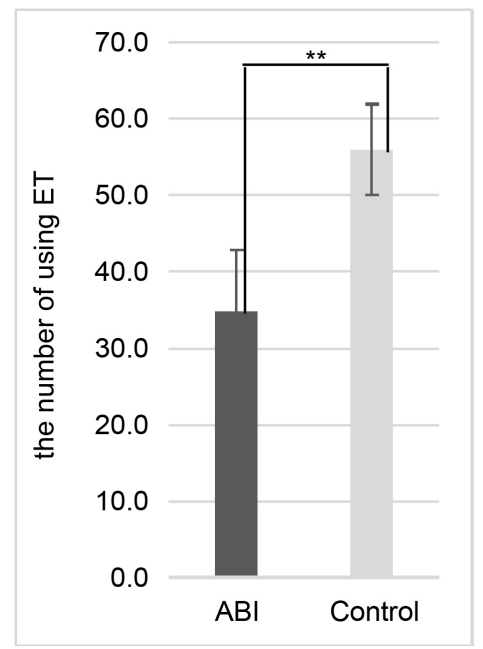

Figure 1. The mean number of ET used by subject with ABI and subject in the control group. The ABI was significantly lower than control in the number of using ET in everyday life ( $\mathrm{p}<0.01$ by conducting Wilcoxon rank sum test).

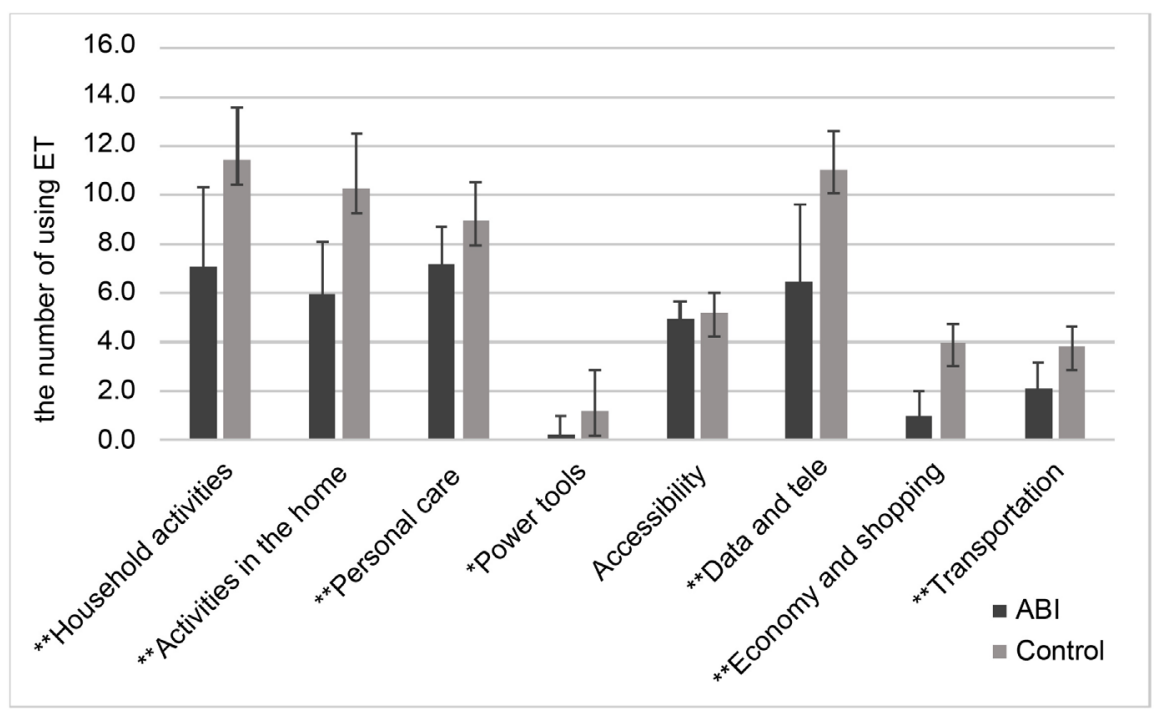

Figure 2. The mean number of ET use in each domain comparing ABI and control. ${ }^{* *} \mathrm{p}<$ $0.01,{ }^{\star} \mathrm{p}<0.05$ by conducting Wilcoxon rank sum test.

\section{Discussion}

In this study, we revealed that people with $\mathrm{ABI}$ used a significantly lower number of ETs than healthy controls (Figure 1). Camilla et al. found that individuals with MCI use lower numbers of ETs compared to controls [19], which is consistent with our results. Considering these results, the number of ETs used is expected to decrease in cases of declining cognitive function, regardless of the cause. Furthermore, in our previous study, we showed that the quality of executive function influences the ability of an individual to use ETs [23]. Executive dysfunction is a subtype or early symptom of MCI [24]; the degree of ET use may have a strong relationship with executive dysfunction, which is controlled by the frontal lobe. 


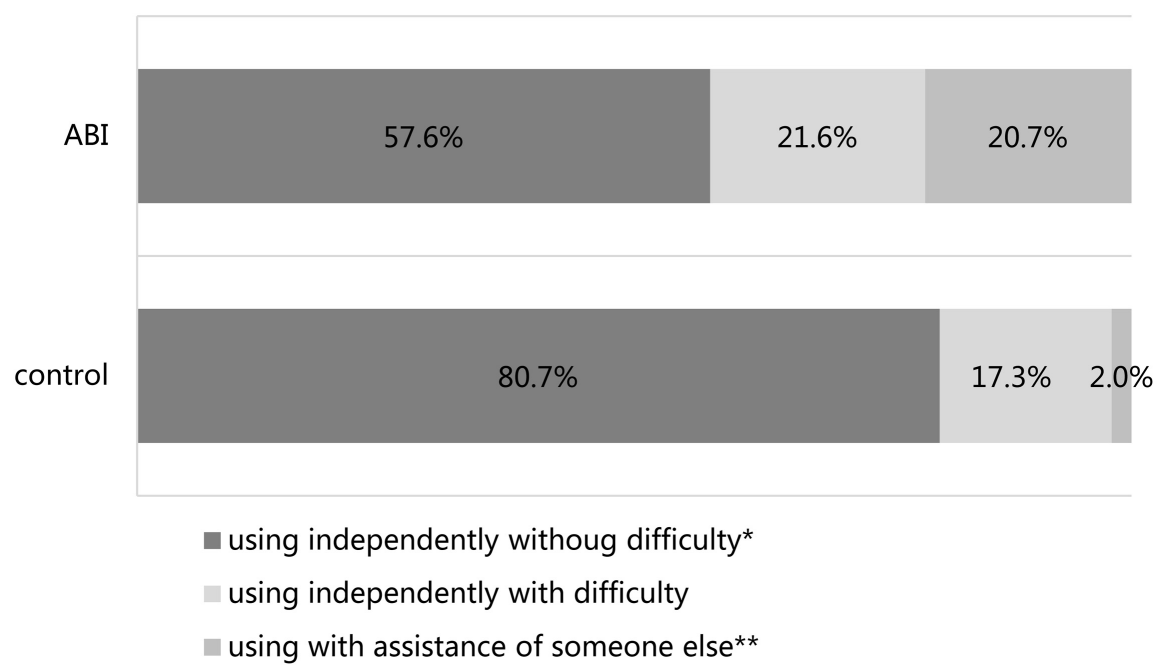

Figure 3. The situation of using ET. The value obtained by dividing the number of ET included in each option by the total number of using ET was calculated in each group. Significant differences were observed between people with ABI and the control group in "use independently without difficulty" and "use with assistance of someone else". There was no significant difference in "use independently with difficulty" between the two groups.

When comparing the ratio of ET use in each domain, the number was significantly low for the ABI group in seven domains, except for the "accessibility" domain (Figure 2). In the "accessibility" domain, all items showed no significant differences in the number of uses. This domain is composed of items highly necessary outside of one's home, such as those that must be used in public toilets, elevators, at department stores or train stations, doors that must be unlocked, or an intercom that must be used when returning home. If the items included in this domain were no longer used, the individual was considered to not leave home often or engage in society. Therefore, in such cases, the number of ETs used is expected to decrease, regardless of the domain.

Individuals with $\mathrm{ABI}$ who cannot use ETs may experience participation restrictions and exclusion from society [15]. The "economy and shopping" and "transportation" domains are deeply related to social participation, and these individuals' low rates of using ETs reflect a decrease in social participation. Furthermore, the association between the condition of using ETs and social participation is related to reemployment, and the ability to use ETs significantly related to a return to work after ABI [13] [14]. When considering the social participation and integration of individuals with $A B I$ back into society, it is necessary to consider their ability to engage with ETs in the "economy and shopping" and "transportation" domains.

The average number of ETs used by people with ABI was significantly lower than that of controls. Moreover, the perceived difficulties of using ET ("use independently with difficulty" + "use with assistance of someone else"; Figure 3) were higher compared to the control group. Various difficulties of using ET have been identified and discussed in recent studies on elderly patients with dementia [11] [25] and people with ABI [15] [21]. Several types of ETs exist, and are es- 
sential for convenient modern day lives [10]. Therefore, the convenient and comfortable daily lifestyle afforded by ET is limited for people with ABI living with fewer ETs.

The degree of perceived difficulty is divided into two levels in the analysis of the ETUQ: "use independently with difficulty" and "use with assistance of someone else". When comparing the ratio of all ETs used between people with $\mathrm{ABI}$ and controls, no significant difference was observed in the "use independently with difficulty" category (Figure 3 ). However, the ratio of subjects who could be categorized as "use with assistance of someone else" was significantly higher in the ABI group. When people with ABI experienced difficulty while using ET, no difference was observed between the number of controls and those with $\mathrm{ABI}$ who attempted to use the ET independently. Therefore, the remaining people with $\mathrm{ABI}$ required assistance from someone else. It is possible that the independent use of ET is important for people's sense of self [12]. When a family member provides care, the stress and anxiety experienced by caregivers is greater [26] [27]. Through interventions focused on the assistance of someone else, it may become possible to reduce the difficulty of using ET by people with ABI, along with improvement in the sense of pride among such clients and to decrease the burden of caregivers.

By evaluating the situation of using ET, specialists, such as occupational therapists who progress therapeutic interventions for people with $\mathrm{ABI}$, can develop an understanding of the difficulties that such clients experience throughout their lives, such as in instrumental activities of daily living, participation in society, personal care, and household activities. The ETUQ, developed as an evaluation tool for investigating an individual's ability to use ET, was used in a comparative study between some countries [28] [29]. It is also used for evaluating mentally deficient people [30], and those with ABI [13] [20]. Investigations using the ETUQ-Japan are useful for enhancing the daily lives of ABI clients living at home in Japan.

\section{Study Limitations}

The target ET in this study existed at the time of the survey. Therefore, the results may be affected when a new ET emerges due to future technological progress. Thus, further investigation is necessary when new technology is developed in the future.

Several people with ABI have problems with their memory whether mild or severe. The participants in our study were required to recall situations of ET use. In some cases, there were differences between the participants and their caregivers when explaining these situations. During the participants' interview, attempts were made to listen to the opinions of the caregivers as well.

\section{Conclusion}

The characteristics of the perceived difficulties of ET use by people with ABI 
were described and revealed through comparison with healthy subjects by using the ETUQ-Japan. The average number of ET used by ABI was significantly low compared to that of controls in almost every domain. The perceived difficulties of using ETs were higher among individuals with $\mathrm{ABI}$ than those among the control group, even though the average number of ETs used by individuals with ABI was significantly lower compared to that used by controls. When these difficulties arose, they were unable to manage using ET by themselves and required assistance. Healthcare workers who intervene in all aspects of the lives of patients may be able to address not only their daily life problems but also problems associated with social participation and the stress of caregivers by paying attention to ETs that require assistance.

\section{Acknowledgements}

The authors would like to thank all the participants and their caregivers for their cooperation in this study, especially for visiting their home. The authors also would like to thank general hospitals, clinics, community workshops specializing in cognitive disorders and Patient-Family Associations which gave us their cooperation when we were recruiting participants.

\section{Declaration of Interest}

The authors indicated no potential conflicts of interest.

\section{References}

[1] Watanabe, S., Yamaguchi, T., Hashimoto, K., Inoguchi, Y. and Sugawara, M. (2009) Estimated Prevalence of Higher Brain Dysfunction in Tokyo. The Japanese Journal of Rehabilitation Medicine, 46, 118-125. (In Japanese with English abstract)

[2] Hachisuka, K., Kato, N., Iwanaga, M. and Okazaki, T. (2011) Incidence of Higher Brain Dysfunction in Japan. Higher Brain Function Research, 31, 143-150. (In Japanese with English Abstract)

[3] Sohlberg, M.M. and Mateer, C.A. (2001) Cognitive Rehabilitation: An Integrative Neuropsychological Approach. Guildford Press, New York.

[4] Ritchie, L., Wright-St Clair, V.A., Keogh, J. and Gray, M. (2014) Community Integration after Traumatic Brain Injury: A Systematic Review of the Clinical Implications of Measurement and Service Provision for Older Adults. Archives of Physical Medicine and Rehabilitation, 95, 163-174.

https://doi.org/10.1016/j.apmr.2013.08.237

[5] Wilson, B.A. (1999) Case Studies in Neuropsychological Rehabilitation. Oxford University Press, Oxford.

[6] Malinowsky, C. and Lund, M.L. (2016) The Match between Everyday Technology in Public Space and the Ability of Working-Age People with Acquired Brain Injury to Use It. British Journal of Occupational Therapy, 79, 26-34. https://doi.org/10.1177/0308022614563943

[7] Häggström, A. and Lund, M.L. (2008) The Complexity of Participation in Daily Life: A Qualitative Study of the Experiences of Persons with Acquired Brain Injury. Journal of Rehabilitation Medicine, 40, 89-95. https://doi.org/10.2340/16501977-0138 
[8] Ramkumar, N.A. and Elliott, T.R. (2010) Family Caregiving of Persons Following Neurotrauma: Issues in Research, Service and Policy. NeuroRehabilitation, 27, 105-112. https://doi.org/10.3233/NRE-2010-0585

[9] Chafjiri, R.T., Navabi, N., Shamsalinia, A. and Ghaffari, F. (2017) The Relationship between the Spiritual Attitude of the Family Caregivers of Older Patients with Stroke and Their Burden. Clinical Interventions in Aging, 12, 453-458. https://doi.org/10.2147/CIA.S121285

[10] Lange, M. and Smith, R. (2002) Technology and Occupation: Contemporary Viewpoints. The Future of Electronic Aids to Daily Living. American Journal of Occupational Therapy, 56, 107-109. https://doi.org/10.5014/ajot.56.1.107

[11] Nygård, L. and Starkhammar, S. (2007) The Use of Everyday Technology by People with Dementia Living Alone: Mapping out the Difficulties. Aging \& Mental Health, 11, 144-155. https://doi.org/10.1080/13607860600844168

[12] Lindén, A., Lexell, J. and Lund, M.L. (2010) Perceived Difficulties Using Everyday Technology after Acquired Brain Injury: Influence on Activity and Participation. Scandinavian Journal of Occupational Therapy, 17, 267-275.

https://doi.org/10.3109/11038120903265022

[13] Lund, M.L., Nygård, L. and Kottorp, A. (2014) Perceived Difficulty in the Use of Everyday Technology: Relationships with Everyday Functioning in People with Acquired Brain Injury with a Special Focus on Returning to Work. Disability and Rehabilitation, 36, 1618-1625. https://doi.org/10.3109/09638288.2013.863388

[14] Kassberg, A.-C., Malinowsky, C., Jacobsson, L. and Lund, M.L. (2013a) Ability to Manage Everyday Technology after Acquired Brain Injury. Brain Injury, 27, 1583-1588. https://doi.org/10.3109/02699052.2013.837196

[15] Engström, A.-L., Lexell, J. and Lund, M.L. (2010) Difficulties in Using Everyday Technology after Acquired Brain Injury: A Qualitative Analysis. Scandinavian Journal of Occupational Therapy, 17, 223-243. https://doi.org/10.3109/11038120903191806

[16] Emiliani, P.L. (2006) Assistive Technology (AT) versus Mainstream Technology (MST): The Research Perspective. Technology and Disability, 18, 19-29. https://doi.org/10.3233/TAD-2006-18104

[17] Fallahpour, M., Kottorp, A., Nygård, L. and Lund, M.L. (2015) Participation after Acquired Brain Injury: Associations with Everyday Technology and Activities in Daily Life. Scandinavian Journal of Occupational Therapy, 22, 366-376. https://doi.org/10.3109/11038128.2015.1011229

[18] Kassberg, A.C., Prellwitz, M. and Lund, M.L. (2013b) The Challenges of Everyday Technology in the Workplace for Persons with Acquired Brain Injury. Scandinavian Journal of Occupational Therapy, 20, 272-281. https://doi.org/10.3109/11038128.2012.734330

[19] Malinowsky, C., Kottorp, A., Wallin, A., Nordlund, A., Björklund, E., Melin, I., Pernevik, A., Rosenberg, A. and Nygård, L. (2017) Differences in the Use of Everyday Technology among Persons with MCI, SCI and Older Adults without Known Cognitive Impairment. International Psychogeriatrics, 29, 1193-1200. https://doi.org/10.1017/S1041610217000643

[20] Fallahpour, M., Kottorp, A., Nygård, L. and Lund, M.L. (2014) Perceived Difficulty in Use of Everyday Technology in Persons with Acquired Brain Injury of Different Severity: A Comparison with Controls. Journal of Rehabilitation Medicine, 46, 635-641. https://doi.org/10.2340/16501977-1818

[21] Lund, M.L., Engström, A.L. and Lexell, J. (2012) Response Actions to Difficulties in 
Using Everyday Technology after Acquired Brain Injury. Scandinavian Journal of Occupational Therapy, 19, 164-175. https://doi.org/10.3109/11038128.2011.582651

[22] Nakata, O., Tanemura, R., Noda, K., Nagao, T. and Sagara, J. (2016) Extraction and Classification of Difficulties Faced by Patients with Brain Injury Living at Home While Using Everyday Technology. Bulletin of Health Sciences Kobe, 32, 55-67.

[23] Nakata, O., Tanemura, R., Nagao, T., Noda, K. and Sagara, J. (2019) Difficulties in Everyday Technology Use of the People with Acquired Brain Injury Living at Home. Asian Journal of Occupational Therapy, 15, 63-68.

[24] Reinvang, I., Grambaite, R. and Espeseth, T. (2012) Executive Dysfunction in MCI: Subtype or Early Symptom. International Journal of Alzheimer's Disease, 2012, Article ID: 936272. https://doi.org/10.1155/2012/936272

[25] Rosenberg, L., Nygård, L. and Kottorp, A. (2009) Everyday Technology Use Questionnaire: Psychometric Evaluation of a New Assessment of Competence in Technology Use. OTJR: Occupation, Participation and Health, 29, 52-62. https://doi.org/10.3928/15394492-20090301-05

[26] Suzuki, Y. and Tanemura, R. (2011) Community-Based Interventional Programmes for Family Caregivers of Persons with Traumatic Brain Injury. Asian Journal of Occupational Therapy, 29, 15-22.

[27] Verhaeghe, S., Defloor, T. and Grypdonck, M. (2005) Stress and Coping among Families of Patients with Traumatic Brain Injury: A Review of the Literature. Journal of Clinical Nursing, 14, 1004-1012. https://doi.org/10.1111/j.1365-2702.2005.01126.x

[28] Patomella, A.H., Kottorp, A., Ferreira, M., Rosenberg, L., Uppgard, B. and Nygård, L. (2017) Everyday Technology Use among Older Adults in Sweden and Portugal. Scandinavian Journal of Occupational Therapy, 7, 1-10.

[29] Malinowsky, C., Nygård, L., Tanemura, R., Nagao, T., Noda, K., Nakata, O., Sagara, J., Rosenberg, L. and Kottorp, A. (2017) Everyday Technology Use among Older Adults in Sweden and Japan: A Comparative Study. Scandinavian Journal of Occupational Therapy, 27, 1-11.

[30] Hällgren, M., Nygård, L. and Kottorp, A. (2011) Technology and Everyday Functioning in People with Intellectual Disabilities: A Rasch Analysis of the Everyday Technology Use Questionnaire (ETUQ). Journal of Intellectual Disability Research, 55, 610-620. https://doi.org/10.1111/j.1365-2788.2011.01419.x 